\title{
O papel da investigação e da inovação
}

https://doi.org/10.21814/uminho.ed.24.11

\section{Eugénio Campos Ferreira}

Eugénio Campos Ferreira (ORCID: 0000-0002-5400-3333) é atualmente Vice-Reitor para a Investigação e Inovação e Professor Catedrático do Departamento de Engenharia Biológica, com doutoramento em Engenharia Química pela Universidade do Porto. Dirige o Programa Doutoral em Bioengenharia. Foi Diretor do Centro de Engenharia Biológica, onde lidera um grupo de investigação em Biossistemas e Vice-Presidente da Escola de Engenharia. É Membro Conselheiro da Ordem dos Engenheiros, tendo sido Presidente do Conselho Nacional do Colégio de Engenharia Química e Biológica. 


\section{A DOENÇA DO CORONAVIRUS 2019 (COVID-19)}

O vírus SARS-CoV-2 (“Severe acute respiratory syndrome coronavirus 2") é um Betacoronavirus pertencente ao género Coronavirus, que se julga originário de hospedeiros como o morcego ou o pangolim. A transmissão efetua-se através de gotículas pelas vias respiratórias, infetando as células através do recetor ACE2 (Angiotensin Converting Enzyme 2). ACE2 está envolvido na função cardíaca e no desenvolvimento de hipertensão e diabetes. A COVID-19 induz um estado pró-trombótico, resultando no desenvolvimento de coágulos sanguíneos arteriais e venosos patológicos. A inflamação resulta frequentemente em distúrbios de hemostasia e coagulação. A inflamação sistémica e a atividade desregulada de citocinas (frequentemente denominada "tempestade de citocinas") associadas à doença COVID-19 é provavelmente um evento crítico no desenvolvimento da coagulopatia. A doença pode resultar em pneumonia, lesão aguda do miocárdio e dano crónico no sistema cardiovascular. Os sintomas de infeção são potenciados em pacientes com problemas cardiovasculares.

Investigadores do Oak Ridge National Laboratory (EUA) publicaram recentemente um estudo (Garvin et al., 2020), com recurso ao supercomputador IBM Summit, propondo um novo mecanismo molecular para explicar o impacto da COVID-19 no corpo humano. Aparentemente, o vírus entra no corpo através dos recetores ACE2 no nariz. Depois, segue para o corpo, entrando noutras células onde ACE2 também está presente, como os intestinos, rins e coração. $\mathrm{O}$ vírus infeta as células que já expressam vários recetores ACE2 e sequestra os próprios sistemas do corpo, induzindo-os a aumentar esses recetores noutros sítios, nomeadamente nos pulmões. Quando o coronavírus atinge sistema renina-angiotensina ${ }^{1}$, faz com que os mecanismos para regular a bradicinina fiquem descontrolados e haja uma acumulação excessiva desta substância nos tecidos do corpo, explicando muitos dos efeitos mortais da COVID-19. O excesso de bradicinina no corpo faz com que os vasos sanguíneos vazem. À medida que isto acontece, os investigadores sustentam que os pulmões podem encher-se de líquido. Adicionalmente, as células imunes também vazam para os pulmões, causando inflamação. A doença também aumenta a produção de ácido hialurónico nos pulmões, formando uma espécie de hidrogel.

\footnotetext{
1 O sistema RAS controla muitos aspetos do sistema circulatório, incluindo os níveis corporais de bradicinina, que normalmente ajuda a regular a tensão arterial.
} 
Investigadores da Columbia University Irving Medical Center sugeriram recentemente (Ramlall et al., 2020) que um dos ramos mais antigos do sistema imunológico, o sistema complemento e a disfunção da coagulação, podem influenciar a gravidade da COVID-19. A equipa americana encontrou evidências que a atividade de coagulação está ligada à gravidade da COVID-19 e que mutações em certos genes dos sistemas complemento e de coagulação estão associadas à hospitalização de pacientes com COVID-19. Entre os resultados que ligam o sistema complemento à gravidade do COVID-19, está a descoberta de que os indivíduos com degeneração macular, relacionada com a idade - um distúrbio causado pelo complemento hiperativo -, têm maior risco de desenvolver complicações graves e morrer de infeção por SARS-CoV-2.

A investigação e a inovação são atividades primordiais na compreensão dos mecanismos de propagação e infeção do SARS-CoV-2, assim como no desenvolvimento de estratégias de prevenção da COVID-19 (incluindo vacinas e novas terapias), de diagnóstico precoce e seu prognóstico, nos estudos clínicos e epidemiológicos, de equipamentos e dispositivos médicos. No seguimento serão apresentadas diversas iniciativas de investigação, desenvolvimento e inovação (I\&D\&I) de âmbito internacional e nacional, fazendo-se referência em particular ao contributo dos investigadores $\mathrm{da}$ Universidade do Minho.

\section{INICIATIVAS DE I\&D\&I DE CONTEXTO INTERNACIONAL}

A Organização Mundial de Saúde (OMS) disponibiliza um portal com uma base de dados sobre a investigação global em COVID-19. A base de dados está disponível para pesquisa e para descarregar. A OMS tem ativado um plano (Blueprint) de investigação e desenvolvimento para acelerar o diagnóstico, o desenvolvimento de vacinas e de terapêutica para este novo coronavírus. O Blueprint visa melhorar a coordenação entre cientistas e profissionais de saúde globais, acelerar o processo de I\&D e desenvolver novas normas e padróes para melhorar a resposta global. Promove os programas "Solidarity" de ensaios clínicos para tratamento e "Solidarity II" de estudos serológicos globais para a COVID-19. 
Um consórcio público-privado de diversas empresas e organizaçôes internacionais criou a base de dados "COVID-19 Research Database" acessível por investigadores académicos e médicos de saúde pública que pretendam realizar estudos com dados reais relacionados com a COVID-19. O acesso está reservado apenas para projetos sem fins lucrativos e não comerciais relacionados com a COVID-19, devendo os resultados ser disponibilizados ao público, de preferência por meio de publicações científicas.

A Comissão Europeia promove uma página específica - European Research Area (ERA) Corona Platform - para centralizar informação sobre investigação e ações contra a COVID-19. Inclui informação sobre o modo como a pandemia afeta as candidaturas e projetos financiados pela CE; extensões de projetos até 6 meses; flexibilidade na submissão de relatórios científicos e financeiros, intermédios e finais; flexibilização nas datas de submissão de entregáveis, marcos e relatórios; e na possibilidade de adiar a data de início do projeto. Enuncia a necessidade de reorientação e adaptação na implementação de projetos do Horizonte 2020, designadamente na reorientação de trabalhos em andamento dos projetos Horizonte 2020 para ajudar a combater o surto de COVID-19.

A comunidade aberta reunida em torno da Plataforma Europeia de Colaboração de Clusters organizou um portal de respostas à COVID-19 por parte dos clusters industriais. São apresentadas mais de 1100 ofertas de empresas encaminhadas para a Comissão Europeia com o apoio da European Cluster Alliance.

O portal Europeu de partilha de dados de investigação COVID-19 (COVID-19 Data Portal), operado pela EMBL-EBI e pela infraestrutura de investigação ELIXIR, disponibiliza sequências de vírus e de hospedeiros, dados de expressão e de sequências e estruturas de proteínas hospedeiras, vias, interações, complexos, alvos e compostos. Também a plataforma OpenAIRE de ciência aberta na Europa, financiada pela Comissão Europeia, promove um portal “OpenAIRE for COVID-19” que dá acesso a dois serviços: (i) “Comunidade Zenovo COVID-19”, operado juntamente com o CERN para coletar resultados de pesquisa que possam ser relevantes para a comunidade científica mundial que trabalha com COVID-19 e SARS-CoV-2; (ii) "OpenAIRE COVID-19 Gateway” de acesso a publicações, dados de investigação, projetos e software que possam ser relevantes para a COVID-19. A UNESCO atribui especial importância à Ciência Aberta no combate à COVID-19, disponibilizando, para o efeito, um 
conjunto de soluções abertas agregadas num portal. Nos EUA, os Institutos Nacionais de Saúde (NIH), através do National Center for Advancing Translational Sciences, promovem o portal “OpenData / COVID-19" disponibilizando em acesso aberto uma coleção de conjuntos de dados selecionados de ensaios relacionados com o SARS-CoV-2 de todos os medicamentos aprovados. Saliente-se que os NIH dispóem de uma página internet agregadora para a COVID-19 em www.nih.gov/coronavirus.

O desafio EUvsVirus é um Hackathon orientado para a luta à COVID-19, apoiado pelo Conselho Europeu de Inovação (EIC) que juntou 2164 equipas multidisciplinares e multinacionais de 40 países, com soluçôes inovadoras durante abril de 2020 e, em seguida, gerou o desenvolvimento de 2235 novas parcerias europeias, ao combinar as 120 melhores equipas com mais de 500 parceiros de apoio dos setores público e privado durante o mês de maio.

Diversos grupos editoriais, responsáveis por catálogos de centenas de revistas científicas, prepararam hubs agregadores de informação sobre a COVID-19. A $\underline{E B S C O}$ promove uma iniciativa de acesso aberto às suas publicações relacionadas com a pandemia. Outras editoras com iniciativas semelhantes incluem a Springer, WILEY, Taylor \& Francis, Cambridge University Press, IEEE e American Chemical Society. A editora da Sociedade Americana de Microbiologia, disponibiliza, após registo, acesso aberto a artigos de virologia básica, tratamento, epidemiologia, diagnósticos clínicos e prevenção. A Elsevier disponibiliza um portal, suportado pela SCOPUS, para pesquisa de informação de competências de investigação e colaborações internacionais, um centro de recursos de pesquisa de publicações, com acesso aberto, enquanto vigorar o estado de emergência de saúde pública (até 28 de outubro de 2020), a textos completos de artigos e capítulos de livros, um "Novel Coronavirus Information Center" e um "Novel Coronavirus Resource Directory". Revistas de renome como a Nature, a Science e The Lancet apresentam iniciativas semelhantes com acesso livre e imediato aos artigos sobre a COVID-19. 


\section{INICIATIVAS E PROGRAMAS DE APOIO E FINANCIAMENTO INTER- NACIONAIS}

O papel da I\&D é uma componente essencial da resposta coordenada da União Europeia à pandemia COVID-19. O financiamento da I\&D está entre as ferramentas de maior impacto a nível Europeu para ultrapassar esta pandemia. A Comissão Europeia (CE) tem em curso um programa de "Resposta Global ao Coronavirus", com medidas globais para acesso universal à vacinação, a tratamento e teste de coronavírus, orçamentado em 15,9 mil milhões de Euros. A CE está a montar um plano de recuperação em que a I\&D desempenha um importantíssimo papel. Esse plano prevê um reforço de 94,4 mil milhões de Euros para o próximo programa-quadro Horizonte Europa, destinado a financiar investigação em saúde e nas transiçôes verdes, digitais e resilientes. Especial atenção será dada ao aumento do apoio à I\&D para a saúde (EU4Health), para as questôes climáticas e à capacitação na resposta a emergências (rescEU). A I\&D surge também explicitamente mencionada como área prioritária no novo instrumento designado por "Plano de Recuperação e Resiliência” que terá uma dotação de 560 mil milhões de Euros.

A Direção Geral de Investigação e Inovação(DG RTD) da Comissão Europeia lançou uma linha de financiamento de 47,5 milhôes de euros através do concurso "SC1-PHECORONAVIRUS-2020: Advancing knowledge for the clinical and public health response to the [COVID-19] epidemic". O "Espaço Europeu de Investigação" (ERA) estabeleceu em abril de 2020 um conjunto de 10 ações prioritárias para o plano de ação "ERAvsCorona”, incluindo a coordenação de apoios à I\&D de combate ao coronavírus, a angariação de financiamento adicional para testes clínicos de largo espectro, o lançamento de uma plataforma de oportunidades de financiamento a projetos de $I \& D$.

A Gavi - Vaccine Alliance, um programa que ambiciona vacinar metade das crianças do mundo contra doenças infeciosas fatais e debilitantes, tem vindo a trabalhar com os países para apoiar a resposta COVID-19 e para manter e restaurar a vacinação de rotina. A Coalition for Epidemic Preparedness Innovations (CEPI), uma parceria global inovadora entre organizações públicas, privadas, filantrópicas e da sociedade civil, lançada em 2017 no Fórum Económico Mundial, para desenvolver vacinas para parar epidemias futuras, juntamente com a OMS e a Gavi e com o apoio do 
ACT-A, lançaram a iniciativa COVAX para assegurar o acesso equitativo às vacinas COVID-19 e encerrar a fase aguda da pandemia até o final de 2021. Nesta data estão em desenvolvimento 321 vacinas candidatas, 33 dos quais estão agora em ensaios clínicos, incluindo nove candidatas apoiadas pela coligação CEPI. Nas 33 em fase de ensaios clínicos há planos de envolver 280000 participantes de pelo menos 470 locais em 34 países diferentes. A iniciativa COVAX integra nove vacinas candidatas apoiadas pela CEPI e há mais nove candidatas em avaliação que não recebem financiamento de I\&D por meio da COVAX.

A parceria público-privado Europeia para a Saúde, através da Iniciativa de Medicinas Inovadoras, financia a investigação e inovação no domínio da saúde, tendo em curso o apoio a 11 projetos de $\mathrm{I} \& \mathrm{D}$ de combate à pandemia.

O Banco Europeu de Investimento e a Comissão Europeia concederam um empréstimo de 75 milhóes de Euros para financiar o desenvolvimento e a produção em larga escala de uma vacina pela farmacêutica alemã CureVac.

As PMEs da União Europeia dispóem do instrumento "EIC Accelerator Pilot" para apoio à inovação no combate à pandemia e à recuperação económica, com uma dotação de 314 milhões de Euros. Até ao momento foram apoiadas 72 empresas.

A C-19 Therapeutic Partnership promove uma colaboração filantrópica de apoio a esforços para investigar e desenvolver tratamentos eficazes contra COVID-19, tornando-os disponíveis para o mercado de forma rápida e acessível. A ONG Foundation for Innovative New Diagnostics (FIND) lançou um programa de apoio ao desenvolvimento de novas tecnologias de diagnóstico. A rede GLOPID-R (Global Research Collaboration for Infectious Disease Preparedness), que junta organizações de financiamento que investem em investigação de doenças infeciosas, trabalha juntamente com a OMS na identificação de prioridades de financiamento de investigação em COVID-19.

O Fórum Económico Mundial (WEF) desenvolveu uma plataforma de ação COVID para mobilizar a cooperação no setor dos negócios. 
A Fundação Bill \& Melinda Gates, que mantém um importante programa de combate a doenças infeciosas (malárias, HIV), investiu 350 milhóes de dólares no apoio à deteção do vírus, a terapêuticas e ao desenvolvimento de vacinas através da iniciativa ACT-A. E anunciou um apoio 1600 milhões de dólares à iniciativa GAVI para os próximos 5 anos.

\section{A I\&D\&I EM CONTEXTO NACIONAL}

A Fundação para a Ciência e a Tecnologia (FCT) e a Agência de Investigação Clínica e Inovação Biomédica (AICIB) promovem o portal Science4COVID para partilha de ideias, ações e publicações. Esta plataforma digital, em parceria com as autoridades de saúde e instituições de investigação científica, pretende mobilizar a comunidade científica em projetos e atividades conjuntas de $I \& D$ que visem o combate à COVID-19. O portal ambiciona agrupar metadados, datasets ou hiperligaçóes, registo de problemas, resultados de investigação em vigilância epidemiológica e outros dados secundários de saúde pública anonimizados necessários ao combate à epidemia por coronavírus, como resultados clínicos, analíticos e demográficos.

A FCT, em colaboração com a AICIB, lançou duas linhas de financiamento de Investigação, designadamente a RESEARCH 4 COVID-19 e AI 4 COVID-19.

O apoio "RESEARCH 4 COVID-19" foi efetuada através de duas chamadas orientadas ao financiamento de projetos e iniciativas de $\mathrm{I} \& \mathrm{D}$, que respondam às necessidades imediatas dos sistemas de saúde na resposta à COVID-19 e a futuras pandemias, através do desenvolvimento de novas ferramentas de prevenção incluindo o desenvolvimento de vacinas, desenvolvimento de novas terapias e de novas estratégias de abordagem terapêutica, métodos de diagnóstico precoce e seu prognóstico, estudos clínicos e epidemiológicos e de avaliação da transmissão da infeção, equipamentos e dispositivos médicos, assim como atividades de I\&D que incluam uma componente sociocultural e açôes de promoção de uma sociedade resiliente com capacidade de enfrentar o atual contexto de incerteza em que vivemos, sobretudo na população mais idosa e em grupos de maior risco. As propostas de I\&D apresentadas deveriam ser de concretização rápida (máximo 6 meses de tempo de desenvolvimento) devendo ser orientadas para 
complementar iniciativas em curso e a reorientação de equipas existentes. O limite máximo de financiamento de cada projeto foi de 30 mil Euros na 1 a edição e 40 mil euros na 2a edição. A dotação orçamental das duas edições atingiu os 3,5 milhões de euros.

O concurso “AI 4 COVID-19”, correspondente à 3a edição de um programa de concursos anuais direcionado para a investigação em Ciência dos Dados e Inteligência Artificial aplicada à Administração Pública, foi exclusivamente orientado para processamento de dados no âmbito da atual pandemia do novo coronavírus SARS-CoV-2 e da doença COVID-19. A iniciativa (em avaliação) destina-se a apoiar projetos e atividades de investigação científica e desenvolvimento tecnológico que contribuam para combater a atual e futuras pandemias através da ciência dos dados e da inteligência artificial, desenvolvidos em parceria entre a administração pública e as instituiçóes de $I \& D$, com ênfase no apoio aos cidadãos e aos serviços e entidades prestadoras de cuidados de saúde, no âmbito da Iniciativa Nacional Competências Digitais e.2030 (Portugal INCoDe.2030).

No âmbito da criação de soluções inovadoras associadas ao Programa de Estabilização Económica e Social (PEES), de resposta à pandemia de COVID-19, a FCT lançou o apoio especial "Verão Com Ciência" para financiar o desenvolvimento de “Escolas de Verão” em Politécnicos e Universidades nacionais, procurando incentivar atividades integradas de $I \& D$ e formação superior presenciais que contribuam para o processo de estabilização económica e social através de qualificação superior a desenvolver no verão de 2020, entre 1 de julho e 30 de outubro. As propostas de "Escolas de Verão" incluem estágios de investigação em unidades de I\&D e/ou instituições públicas ou privadas, e devem ser de concretização rápida, com um horizonte de 3 meses de desenvolvimento. Foram concedidos apoios para bolsas de $\mathrm{I} \& \mathrm{D}$ ou extensão de bolsas de ação social escolar para atividades presenciais de formação e investigação em Politécnicos e Universidades, de estudantes e jovens em estreita articulação com unidades de I\&D e com a possibilidade de estágios em instituições públicas ou privadas.

A FCT atribuiu ainda bolsas de formação avançada através do concurso DOCTORATES 4 COVID-19, especificamente aberto no âmbito do novo coronavírus SARS-CoV-2 e da doença COVID-19, orientado para a obtenção de novos conhecimentos que permitam criar competências para respostas a esta e a futuras 
pandemias e que se traduzam em medidas de prevenção eficientes, melhores cuidados de saúde e a um apoio efetivo aos cidadãos. O aviso contemplava o apoio a candidaturas em qualquer área científica que contribuam para os seguintes objetivos: epidemiologia e fatores de risco de infeção e doença grave pelo vírus; a interação Homem-animal, mecanismos de resistência e de transmissão interespécies do vírus e o risco de pandemias; estratégias de prevenção e preparação para novas epidemias, incluindo vacinas; abordagens inovadoras, incluindo novos métodos e novas tecnologias, para o diagnóstico da doença; caracterização dos mecanismos de infeção viral; caracterização da resposta do hospedeiro, imunológica celular e serológica, à infeção pelo vírus, impacto da idade e comorbilidades; desenvolvimento de novas terapias e de novas abordagens terapêuticas, incluindo equipamentos de suporte de vida e de proteção individual para o combate à doença; repercussões da infeção viral na saúde materna e no recém-nascido; impacto psicológico e alteraçóes de comportamento associadas à pandemia.

A FCT promoveu ainda o concurso "GENDER RESEARCH 4 COVID-19" de apoio especial a 16 projetos de investigação sobre o impacto da emergência de saúde provocada pela COVID-19 nas desigualdades de género e violência contra as mulheres e violência doméstica. Os projetos são orientados para a produção e difusão de conhecimento sobre os impactos de género da pandemia provocada pela COVID-19 e da divulgação dos planos de contingência e medidas adotadas para a conter e resolver.

Na vertente da inovação, a Agência Nacional de Inovação S.A. (ANI) promoveu a Iniciativa à Investigação Aplicada Nacional - “INOV 4 COVID-19”. Foi lançado um concurso, em colaboração a AICIB, para financiar o desenvolvimento imediato de projetos de aplicação efetiva no curto prazo de I\&D e inovação tecnológica desenvolvidos pelos Centros de Interface e Laboratórios Colaborativos no âmbito da pandemia SARS-CoV-2 / COVID-19, para impulsionar a criação de novas cadeias de produção nacional essenciais a esse combate. A ação visava financiar projetos de desenvolvimento de sistemas de ventilação e ventiladores, sistemas de triagem, kits de diagnóstico e teste ou elementos para os mesmos, equipamentos de proteção individual e outros equipamentos de sistemas de apoio e desinfeção. Foram financiados 3 projetos:

1. Projeto "Atena" (CEiiA - Centro de Engenharia para o Desenvolvimento de Produto), num montante de 2,6 milhões de euros, para conceção, produtização e 
industrialização de um ventilador médico invasivo de montagem simples e produção descentralizada, para ambiente hospitalar, com conceção, teste e preparação do processo de industrialização em Portugal. Estimativa de produção de 1.500 ventiladores para o ano de 2020.

2. Projeto Calçado Solidário @FOOTURE (Centro Tecnológico do Calçado de Portugal), num montante de 77 mil Euros. Trata-se de uma iniciativa que mobiliza e envolve empresas do cluster do calçado e dos setores dos componentes plásticos e da moda, que tem como principal objetivo a certificação de equipamentos de proteção individual (EPI), incluindo calçado, máscaras e viseiras.

3. Testes COVID-19 (iBET - Instituto de Biologia Experimental e Tecnológica), num montante de 40 mil Euros, para disponibilização de testes à COVID-19 mais rápidos e baratos, que permitiram aumentar a capacidade instalada até seis vezes em todo o mundo, através da substituição do método baseado em qRT-PCR por um método mais sensível e baseado em reagentes e equipamentos mais básicos e baratos.

A ANI lançou ainda um Aviso específico para apoio a projetos de I\&D, a realizar em parceria entre empresas e entidades não empresariais do Sistema de I\&I, no contexto de medidas de auxílio estatal de apoio à economia no atual contexto do surto de COVID-19. Adicionalmente, a ANI disponibiliza um portal de divulgação de "Soluçốes e Tecnologias para a COVID-19" para melhorar a visibilidade do esforço das startups, empresas e entidades do sistema científico e tecnológico na resposta aos impactos negativos da COVID-19.

A Fundação Calouste Gulbenkian (FCG) criou um fundo de emergência num montante inicial de 5 milhóes de euros para apoiar cinco áreas: Saúde, Ciência, Sociedade Civil, Educação e Cultura. O apoio na área da ciência destina-se essencialmente a reforçar o financiamento do Instituto Gulbenkian de Ciência (IGC), na área da imunologia, genómica, virologia e relação micróbio-hospedeiro, destinado a aumentar o conhecimento científico relativo à 2019-nCoV/COVID-19. Esta iniciativa será aberta e coordenada com outras Instituições e Estruturas de investigação em Portugal e no Estrangeiro. O IGC, juntamente com outras Instituições na área de Lisboa, está a 
desenvolver novos métodos de diagnóstico para produção e implementação em massa e participa no consórcio Serology4COVID para desenvolvimento de ensaio serológico para a população portuguesa. A FCG está a organizar uma série de eventos intitulada "COVID-19: E depois?" em que quatro dezenas de nomes consagrados e jovens promessas deixam pistas para um futuro pós-COVID.

A Fundação Luso-Americana para o Desenvolvimento (FLAD) apoia a criação de Biobanco no Instituto de Medicina Molecular João Lobo Antunes (iMM) para conhecer melhor a COVID-19 através da recolha de amostras biológicas de doentes infetados. O objetivo é aumentar o conhecimento sobre o vírus para desenvolver respostas terapêuticas e descobrir porque o vírus se comporta de forma diferente em diversos grupos populacionais.

A Fundação La Caixa promoveu o concurso CaixaImpulse COVID-19 para apoio a projetos clínicos e translacionais direcionados para a prevenção, tratamento, monitorização, gestão ou diagnóstico de COVID-19 (incluindo ferramentas e planos de prevenção, implantação de ferramentas de diagnóstico ou deteção precoce, desenvolvimento de novas terapias ou reposicionamento de tratamentos específicos, além do desenvolvimento de modelos de previsão ou estratégias de gestão de emergências, entre outros). $\mathrm{O}$ concurso foi direcionado a projetos, enquadrados nas áreas científicas das Ciências da Vida ou Ciências Médicas e da Saúde, com atividades preliminares de validação e um foco claro na inovação. O montante máximo de apoio financeiro era de 300 mil euros, num máximo de 24 meses.

A comunidade tecnológica, constituída pelo Movimento \#Tech4COVID19, juntou-se em torno do portal tech4COVID. Esta comunidade, iniciada por diversos fundadores de startups tecnológicas portuguesas, agrega mais de 5000 pessoas de entre engenheiros, cientistas, designers, marketeers, profissionais de saúde, entre muitas outras especialidades de 250 empresas diferentes, para o desenvolvimento de soluções tecnológicas que ajudem a população a ultrapassar o desafio da COVID-19. As iniciativase desenvolvimentos incluem apps para infografia da rastreamento da epidemia COVID; campanhas de recolha de donativos para aquisição de bens e consumíveis hospitalares; plataformas para consultas remotas de medicina e psicologia; aplicações de repositórios de informação científica de artigos sobre COVID de apoio aos médicos; plataforma 
para encomenda online de medicamentos em farmácias; iniciativas para entregas ao domicílio incluindo transporte de refeições; aplicação para gestão de filas (senhas virtuais) em espaços comerciais; angariação de computadores para estudantes carenciados; plataforma para empresas locais venderem vouchers a serem resgatados após a crise; plataforma para trocas/empréstimos temporários de equipas de técnicos; plataformas para gestão de transporte e alojamento para profissionais de Saúde; e diversos projetos online - ver diretório em www.covindex.pt.

A 18 de maio de 2020 o Governo lançou a iniciativa "Skills 4 pós-COVID - Competências para o futuro", com objetivo de reforçar e valorizar a resposta conjunta dos sistemas de ciência e ensino superior aos desafios induzidos pela COVID-19 em estreita articulação com empregadores públicos e privados, designadamente:

1. Identificar os principais constrangimentos, desafios e oportunidades que a pandemia COVID-19 introduz e/ou aprofunda nas atividades de ensino superior e na sua relação com a ciência e os mercados de trabalho, públicos e privados;

2. Antecipar o papel que as Instituiçóes de Ensino Superior terão no período pós-COVID-19, avaliando não só as transformaçôes socioeconómicas em curso, em particular no que diz respeito à natureza das competências procuradas, mas também como é que o sistema de ensino superior pode influenciar este processo de transição;

3. Identificar e fomentar novas abordagens nos mais diversos níveis de funcionamento e organização das instituições de ensino superior, que permitam capacitar a resposta aos desafios introduzidos pela COVID-19. Incluem soluçóes inovadoras a nível institucional, de forma colaborativa e em rede, estimulando arranjos colaborativos e consórcios de formação avançada, investigação e inovação, envolvendo instituiçóes de ensino superior com empregadores públicos e privados e/ou outras entidades públicas ou privadas.

\section{O CONTRIBUTO DA UNIVERSIDADE DO MINHO}

A Universidade do Minho empenhou-se, desde a "primeira hora", no desenvolvimento de soluçôes, serviços, dispositivos e equipamentos para a luta contra a COVID-19. 
As iniciativas incluem ferramentas de prevenção, abordagens terapêuticas, realização de testes diagnóstico precoce, estudos clínicos e epidemiológicos, desenvolvimento de equipamentos e dispositivos médicos. No seguimento mostra-se a proatividade e voluntarismo dos nossos investigadores nos últimos seis meses.

Oito investigadores da Universidade do Minho viram as suas candidaturas ao Programa Research4COVID-19 da FCT selecionadas para financiamento. A tabela seguinte apresenta os 8 projetos que receberam financiamentos médios de 40 mil Euros na 2 a edição (as 3 primeiras entradas) e 30 mil Euros na 1a edição.

\section{Projeto}

COVID2ndID - Improved detection of COVID-19 secondary bacterial infections for efficient therapy

Fenótipos de infeção por SARS-CoV-2: análise integrada longitudinal de coorte para criação de modelo preditivo de prognóstico

Effects of COVID-19 pandemic on psychological status and cognitive function of senior adults: follow-up of an established aging cohort

Which, when and for who? Serodiagnosis as a tool to complement diagnosis and evaluate population immunity against SARS-CoV-2

Develop fast, highly accurate, low-cost PCR-based protocol to test SARS-CoV-2

Promoting Mental Health During Pandemic - a digital platform for monitoring and intervention

Projeto GIRO: Uma plataforma digital de atividades para séniores em isolamento social

Desenvolvimento de espaços para a esterilização por irradiação ultravioleta-C (UV-C) em larga escala de Equipamentos de Proteção Individual (EPIs) nos hospitais para a sua reutilização

\section{Investigador Responsável}

Sílvio Roberto Branco dos Santos

Pedro Miguel Guimarães Marques da Cunha

Teresa de Jesus da Costa Castanho

Margarida

Correia-Neves

Maria Isabel

Mendes Veiga

Pedro Ricardo

Luís Morgado

Nadine Correia Santos

Andrea Zille

\section{Centro de Investigação}

Centro de Engenharia Biológica

Instituto de investigação em Ciências da Vida e da Saúde (ICVS)

ICVS

ICVS

ICVS

ICVS

ICVS

Centro de Ciência e

Tecnologia Têxtil 
À 3a edição do concurso "AI 4 COVID-19”, de investigação em Ciência dos Dados e Inteligência Artificial aplicada à Administração Pública, foram apresentadas duas candidaturas que aguardam avaliação.

No âmbito do Apoio especial "Verão com Ciência" a Universidade do Minho viu aprovadas para financiamento seis ações de formação. Estas Escolas de Verão receberam um financiamento médio de 27 mil Euros para bolsas de estágios de investigação em unidades de I\&D durante 3 meses. As temáticas incluíram a produção de máscaras para a prevenção da COVID; o desenvolvimento de modelos metabólicos; a comunicação e cultura para o desenvolvimento; a psicologia clínica; investigação e formação em Português; e a mobilidade, violência, memória e criatividade em África.

A FCT atribuiu 50 bolsas de formação avançada, de investigação para Doutoramento, através do concurso DOCTORATES 4 COVID-19, especificamente aberto no âmbito do coronavírus SARS-CoV-2 e da doença COVID-19. O concurso recebeu 128 candidaturas e a UMinho obteve o apoio em 5 candidaturas:

\section{Tema}

COVID-19 Pandemic Impact on Domestic Violence

- The Voice of Victims and Front-Line Professionals

COVID-19 e a violência doméstica: impacto na saúde mental das vítimas em casa-abrigo

The experience of becoming a mother in a pandemic period:

Lessons learned to move forward

COVID-19 as an adverse childhood event: Environmental contributions to risk and resilience for children's neurobiological and socio-emotional functioning

A Systems Biology approach to model COVID-19 phenotypes and drive drug discovery

\section{Centro de Investigação}

Centro de Investigação em Psicologia

Centro de Investigação em Psicologia

Centro de Investigação em Psicologia

Centro de Investigação em Psicologia

Centro de Engenharia Biológica

A UMinho participou no desenvolvimento do ventilador médico invasivo para aplicação nos doentes que ficam em estado crítico e que necessitam de ventilação externa para conseguir respirar e combater a doença. O projeto Atena, liderado pelo 
CEiiA e financiado pela ANI no âmbito da Iniciativa à Investigação Aplicada Nacional - "INOV 4 COVID-19", teve o envolvimento de uma equipa da nossa Escola de Medicina coordenada pelo Prof. José Miguel Pêgo. Esta equipa, através do Centro Clínico Académico de Braga, realizou ensaios com o ventilador pulmonar invasivo em modelos vivos, animal e humano. $\mathrm{O}$ trabalho inicial de desenvolvimento do protótipo funcional resultou do trabalho conjunto de 106 engenheiros de várias áreas do CEiiA e de intensivistas, pneumologistas, anestesistas e internistas de hospitais públicos e privados. Para além do financiamento da ANI teve o apoio da Fundação EDP, Fundação Calouste Gulbenkian, Fundação La Caixa/BPI e REN.

A contribuição da I\&D da UMinho não se faz somente através de projetos financiados por programas específicos orientados para a COVID-19. Na edição de julho de 2020 do NÓS - Jornal Online da UMinho (Vieira da Silva, 2020) são apresentadas duas dezenas de projetos de investigação com a liderança/participação de investigadores da UMinho. A UMinho lidera estudos europeus, participa em investigaçóes internacionais e promove trabalhos acerca das implicações da COVID-19 na sociedade. Refira-se a título de exemplo alguns desses trabalhos:

- entender o impacto da atual pandemia no ensino da Optometria a nível Europeu;

- liderança do estudo mundial sobre a resposta de infraestruturas críticas (como sistemas hospitalares, de transportes, de energia, de telecomunicações, de distribuição e financeiros) na pandemia;

- participação em estudo internacional para determinar a incidência da pandemia, estimando o número de casos reais com sintomas de COVID-19 e a sua evolução em 11 países;

- identificação de mutações nos genomas de SARS-CoV-2 que podem ter implicações importantes no diagnóstico do vírus causador da COVID-19;

- coordenação nacional de um estudo sobre a avaliação do impacto da COVID-19 na saúde da população mundial;

- impacto da pandemia de COVID-19 na saúde mental perinatal de 11 países; 
- envolvimento académico de estudantes do ensino superior na fase de isolamento social em Portugal;

- estudo sobre a importância dos processos cognitivos de autorregulação como ferramenta essencial na prevenção e mitigação dos efeitos negativos da COVID-19 (ou situações pandémicas similares) na saúde física e mental;

- intervenção de ajuda psicológica, implementada por telefone, de forma a fornecer ajuda psicológica;

- avaliação da literacia em saúde relacionada com a COVID-19 em estudantes do ensino superior em 38 países europeus;

- impacto da resposta ao surto na Europa em pessoas vulneráveis, especialmente idosos, por meio de um novo conceito holístico e multidisciplinar de experiência em tratamentos;

- estudo sobre o ensino e avaliação à distância em tempos de COVID-19 nos Ensinos Básico e Secundário;

- bem-estar e satisfação dos professores com a profissão, antes e durante a pandemia;

- conhecimentos, opinióes e comportamentos sobre a COVID-19 no Ensino Secundário;

- Jornalismo em tempo de pandemia;

- efeitos do estado de emergência no Jornalismo;

- perceção sociológica do regresso ao trabalho pós-COVID-19;

- utilização de aplicaçôes móveis durante o isolamento social/quarentena;

- educação durante a pandemia;

- tendências de pesquisa dos portugueses, através do Google, durante a quarentena;

- perceção sobre as informações geradas durante a COVID-19;

- impactos da COVID-19 no setor cultural português. 
No domínio da transferência de tecnologia, diversos investigadores da UMinho apresentaram, através da interface TECMINHO, candidaturas a projetos de inovação no âmbito do aviso específico da ANI para apoio a projetos de I\&D, a realizar em parceria entre empresas e entidades não empresariais do Sistema de I\&I. As tecnologias a desenvolver incluem sistema de microcápsulas para inativação do coronavírus; máscara de proteção nível II reutilizáveis; máscara FFP2 termoformadas, a partir de um filtro com gradiente de capacidade de filtragem (nano/micro) para utilização em contexto profissional; equipamentos de proteção individual (EPI) ativos com base em fios multifuncionais; dispositivos para a esterilização por irradiação UV-C) em larga escala de EPIs; EPIs reutilizáveis com funcionalização anti bacteriológica e antivírica para contexto profissional; soluções para desinfeção de pessoas e objetos e controlo de temperatura corporal no contexto da pandemia COVID-19; produção de bioetanol a partir de subprodutos de produção de bolacha.

De realçar o papel de investigadores ligados ao centro de investigação HASLab na coordenação e participação na equipa de desenvolvimento da aplicação para telemóveis STAYAWAY COVID, que tem como objetivo auxiliar o país no rastreio da COVID-19.

\section{CONCLUSÕES}

As respostas à COVID-19 apresentadas neste capítulo, em que se redirecionam fundos de milhares de milhões de Euros para uma agenda de recuperação económica assistida pela $I \& D$, devem permitir criar um futuro melhor para toda a vida na Terra. A crise pandémica do coronavírus será certamente uma oportunidade para um futuro, onde a ciência, a tecnologia e a inovação, conjugadas com a evolução da economia e da sociedade, terão um papel primordial como vetores impulsionadores dessa mudança e podem ser os meios de alcançar um futuro sustentável, equitativo e resiliente para a civilização humana e a biosfera. O risco de acontecer exatamente o oposto é um risco que a humanidade não pode correr. 


\section{REFERÊNCIAS BIBLIOGRÁFICAS}

Garvin, M. R., Alvarez, C., Miller, J. I., et al. (2020). A mechanistic model and therapeutic interventions for COVID-19 involving a RAS-mediated bradykinin storm. eLife 9:e59177. https://doi.org/10.7554/ eLife.59177.

Ramlall, V., Thangaraj, P.M., Meydan, C. et al. (2020). Immune complement and coagulation dysfunction in adverse outcomes of SARS-CoV-2 infection. Nature Medicine (in press). https://doi.org/10.1038/s41591$\underline{020-1021-2 .}$.

Vieira da Silva, D. (2020). Estamos a estudar a pandemia. Nós - Jornal Online da UMinho 98, Consultado em http://www.nos.uminho.pt/Article.aspx?id=3502. 